\title{
Self-Entrepreneurship, Trade Culture and Domestic Economy: A Social Radiography of the Sharshari Traders in Dire Dawa
}

\author{
Tensay Hailu ${ }^{1}$, Desta Tegegne ${ }^{2, *}$ \\ ${ }^{1}$ Department of Social Anthropology, Wolaita Sodo University, Sodo, Ethiopia \\ ${ }^{2}$ Department of Civic and Ethical Studies, Wolaita Sodo University, Sodo, Ethiopia \\ Email address: \\ dtegegne@ymail.com (D. Tegegne), destategegne@wsu.edu.et (D. Tegegne) \\ ${ }^{*}$ Corresponding author
}

To cite this article:

Tensay Hailu, Desta Tegegne. Self-Entrepreneurship, Trade Culture and Domestic Economy: A Social Radiography of the Sharshari Traders in Dire Dawa. Journal of Human Resource Management. Vol. 7, No. 2, 2019, pp. 49-56. doi: 10.11648/j.jhrm.20190702.13

Received: May 18, 2019; Accepted: June 24, 2019; Published: August 23, 2019

\begin{abstract}
This paper is an ethnographic research that tried to study former women merchants who use to trade in between Dire Dawa and Djibouti including small towns along the Ethio-Djibouti railway stations. Moreover, the paper introduces women cross border traders locally known as Sharshari. Here, family, educational and economic background of the traders are revealed, some ambivalent conceptions of the society on Sharshari trader are seen and last but not the least the central position of women traders at domestic activities appraised. The research further describes the domestic economy of those traders who use to trade in between Dire Dawa, Ethiopia and the city of Djibouti, Djibouti republic. Methodologically the research is crafted qualitatively. The views of 10 informants that include women traders; train drivers, local elders and former labor workers of the Sharshari traders are incorporated. The methods of data collections are also diversified in a bid to get more reliable, cross checked and deep empirical evidences. Hence, methods like interviews, observations, informal conversation, focus group discussions and participant observations are used to inquire and grasp information that are best fitting to the objectives of this research. Using the above mentioned methods, the research has got the following findings. Here, Sharshari trans-local traders were prominent traders who used to trade commodities in small town between Dire Dawa and Djibouti. Majority of the traders are uneducated. Most of them have learned the business from their families who use to generate income through such trading activities between small towns in the above mentioned small towns. Since Sharshari are women in gender, they had to execute different activities in their respective household.
\end{abstract}

Keywords: Sharshari, Cross Local Trade, Domestic Responsibility and Self-entrepreneurship

\section{Introduction}

Railway transportation has played massive socio economic importance to the development of Dire Dawa city [1]. The establishment of the city of Dire Dawa was directly tied up with the introduction of railway transportation in the city. ${ }^{1}$ [2]. The unveiling of train transportation system was a catalyst for the expansion and diversification of new

\footnotetext{
1 Elders claim that there were only scattered settlements where pastora populations are located below the foothill of Harar Plateau. Moreover, the current down towns of the city were covered by Acacia trees as nobody was dared to live in it.
}

economic systems like trading; service sectors and industry settings in Dire Dawa [1]. A Trans-local trading activity in this regard was the economic sector emerged with the introduction of railway transportation in the city.

A trans-local trading activity was predominantly carried out by women merchants of the eastern corridor ${ }^{2}$. Although some men merchants were trading between Djibouti and Dire Dawa, women merchants outnumbered men merchants. It is commonly assumed that men's engagement in the formal

2 Sharshari is believed to be a geminated two Arabic words shara'a which means to get involved in and shar'i perform something by moving along. Elaborated discussion will be made in chapter three of this paper. 
economic sector would be one of the major reasons explaining their minor involvement in 'informal' activities ${ }^{3}$ [3]. On top of that, men tend to value the 'formal' working positions offered by the railway company ${ }^{4}$ Due to this reason, therefore, women had controlled the business held through the railway transportation.

The main focus of this research is therefore on those women trans-local Sharshari traders who were trading in between Dire Dawa and Djibouti using train transportation. Here, the Sharshari traders were trading both by crossing Ethio-Djibouti border and also in between towns that are located along the railway lines of the eastern corridor leading to Djibouti. Those women merchants, who were trading between Djibouti and Dire Dawa, were bringing different electronic materials, cloths, food stuffs and consumer goods from Djibouti to Dire Dawa. And they go back to Djibouti with some agricultural products including local spices and chat.

The involvement of women in trans-local trading activities has enabled them to reap both social and economic benefit. Due to their economic strength therefore, those women became heads and bread winners of their respective households. Moreover, as a result of economic networks that they had in different markets of the city, they remained influential people throughout the market chains of the eastern corridor.

\section{Objectives}

The overall objective of this research is to study former women merchants who use to trade in between Dire Dawa and Djibouti including small towns along the Ethio-Djibouti railway stations. Specifically the study aimed to:

i. Introduce about women cross border traders locally known as Sharshari;

ii. Reveal the family, educational and economic background of the traders;

iii. Clarify some ambivalent conceptions of the society on Sharshari trader;

iv. Appraise the central position of women traders at domestic activities; and,

v. Describe the domestic economy of those traders who use to trade in between Dire Dawa, Ethiopia and the city of Djibouti, Djibouti republic.

\footnotetext{
3 In his early defense of informal sector concepts, economic anthropologist Lipton (1984) has said the informal sector has discredited on the account of three alleged deficiencies: misplaced dualism, misplaced isolation and confusion. $\mathrm{He}$ then goes on to specify each critique. Misplaced dualism refers to the fact that in practice there is no clear split between formal and informal sector rather there is a continuum. Misplaced isolation is the neglect of the fact that the relationships of the informal sector to the rest of the economy are not investigated. Under the third critique, that of confusion, is the ideas that the characteristics of the informal sector are not well spelt out

4 However, due to the absence of quantitative and qualitative investigations on the railway traders between Dire Dawa and Djibouti, this gender cleavage along formal/informal economic sectors could not be clearly established in the present study.
}

\section{Methods and Sources of Data}

In research of this kind qualitative research approach is more advisable. Qualitative data provide general elaborations, explanations, meanings and relatively new ideas. Taking all these into account, qualitative research approach, is used for this study. Among the qualitative research designs, for the purpose of this study, ethnographic research design is used.

The views of 10 informants that include women traders; train drivers, local elders and former labor workers of the Sharshari traders are incorporated. The tools of data collections are also diversified in a bid to get more reliable, cross checked and deep empirical evidences. Hence, tools like interviews, observations, informal conversation, focus group discussions and participant observations are used to inquire and grasp information that are best fitting to the objectives of this research.

\section{Result and Discussion}

\subsection{Conceptualizing Sharshari Traders}

As far as the etymological root of the word Sharshari is concerned, most of my informants are not aware of how and when the word Sharshari is used to describe trans-local trading business through the railway transportation. However, some of my informants assume that the word Sharshari is a geminated word believed to come from two Arabic words shara'a which means to get involved in or to perform a project and shar' $i$ which means the one who performs something by moving along. Hence, Sharshari is used by Somali, Afar, Oromo and Harari (Adare) people to designate merchants involved in trading activities by moving along the old railway linking the city of Dire Dawa to Djibouti city and port on the red sea.

Even though women Sharshari traders were outnumbering men Sharshari traders ${ }^{5}$ there was considerable number of men Sharshari who were working as a trader along the railway line. According to most of my key informants however, women merchants were dominated the business because of their negotiation skills and ability of seducing customary and security officers who by far could determine the success of the Sharshari traders. Seduction in this regard to help women to pass checkpoints and refrain customary duties after enticing (trying to be attractive and able to arouse sexual desire) those officers working around customary and security checkpoints along borders and railway stations. As a result of the strategy of seduction, most women Sharshari were profitable as they were curving customary duties in which men Sharshari were paying to pass check points. Women's profitable venture was gradually helped them to dominate trading held through the Railway transportation.

According to my informal conversation with some of my

\footnotetext{
5 Elsewhere in Africa, Muzvidziwa (2005) has described that women are overwhelmingly dominated cross bordering trade between Zimbabwe and South Africa because they simply get excuse of security guards along the borders of the two countries unlike men who the security guards are not relieving them easily.
} 
key informants, Sharshari traders were used to seduce and solicit the one who is in their way to confiscate their commodities. Their action of seducing might include the use of charm (a verbal communication which attract the listeners), salesmanship (the skill of selling and persuading people) and the use of incensory praises to attract and convince anyone who is standing as an obstacle of their business. However, informants are a bit dreading to explain and to some extent compromise the way they were working with stakeholders and their interaction with officers along border checkpoints.

According to most of my key informants, being a Sharshari trader is conceptualized not only as a trader who exchanges goods and services in different market places. However, being a Sharshari trader is to be bread winner of household, leading social settings of their respective community and stimulant of markets located along the railway. Most of my informants define trade not only as exchanging activities of goods and services at market places but also as it is their culture, their mode of subsistence and also their means of exchanging information, interaction and creating social ties. Furthermore, some Sharshari believe engaging in trans-local trading activity is what they are inherited from their families and what they are going to transfer it to their children. Hence, trade is hereditary business for some of the Sharshari traders and culture for all those former trans-local traders.

In addition, Sharshari traders were believed to have full information of what is happening across different areas, check points, border areas, markets and even what happen to fellow Sharshari traders. Besides, the one who have more information on the above mentioned issues are labeled as the best Shershari as the social position of being best sharshari will create power relation between and among sharshari traders.

\subsection{The Background of Sharshari as Female Entrepreneurs in the Railway City of Dire Dawa, Ethiopia}

Sociologists conceptualize women as one among social groups vulnerable to different socio economic problems and challenges [4]. Particularly, those women who based their life in rural areas are more susceptible for different challenges as they were forced to remain only at their agricultural fields and households [5]. This is due to the long standing gender based division of labor and discriminations that has been ingrained in the whole social system ${ }^{6}$.

However, countering the rural and gender determinism of women, Sharshari traders of Dire Dawa were active in outdoor economic activities despite the widely portrayed discrimination of women at working places. The family

6 The dichotomy of public domestic sphere is now getting a newer dimension. Previously the domestic sphere was believed to be the fatal reason why women are disempowered. It was also taught the coming of women to the public sphere would become the answer for women mainstreaming and empowerment. However, recent studies are showing the involvement of women in the public sphere might not guarantee the power that women are demanding thoroughly (White 1982, Huntington, 1975 and Lewellen, 2003). background and ethnic membership to the Issa Somali are widely presented as the means to survive such difficulties in the Sharshari business.

\subsubsection{Family Background}

According to the first FGD participants, most families of Sharshari traders were coming from different parts of the country mostly from the areas in and around railway stations along the railway lines. Small railway towns like Shinile, Melka Jebdu, Harewe, Adigala and Dewelle areas were the genesis of majority Sharshari traders and their families. According to most of my informants, there were many residents of Dewelle who were Sharshari traders and work in between their border town of Dewelle and Alisebih ${ }^{7}$. Hence, Sharshari traders of Dewelle were only coming to Dire Dawa for marketing their commodities since Dire Dawa was the hub of markets in the eastern corridor ${ }^{8}$.

Adversely however, majority of trans-local traders according to my key informants, were either residents of the city of Dire Dawa or migrant women who came to the city due to different social and economic reasons. Participants of the first FGD session stated that some women were migrating to the city due to different family related inconveniences like conflict with members of their family and economic hardships within their respective households. After their arrival to the city of Dire Dawa those who have relatives in the city stay at their relative's house and those who haven't would engaged in some pity labor activities until they accumulate adequate capital for Sharshari trading.

Those women whose relatives are Sharshari traders were easily acquainted with trans-local trading. Here, there were huge numbers of ethnically Isa Somali women traders since vast amount of Isa were/are living in the areas where railway stations are located. Moreover, informants have claimed that Issa Somali women traders (Sharshari) are mushroomed over the eastern railway corridor because; most workers of the railway company are ethnically Issa Somalis whose social and economic networks extend up to the city of Djibouti. Hence, family and ethnic cliché to the Issa Somali clanship was vital to break through the business and the railway social space.

Contrary to those whose relatives are Sharshari traders and ethnically Issa Somali, those who haven't connected to the bigger Issa ethnic clinch and Sharshari's social spaces needs to come across some challenges ahead. Zahra, who is key informant for this research has said that she came to the city with her family who were living at Melka Jebdu. Zahra continued:

When I came to the city around 1950, there was attractive and profitable trading business which forced me to involve in it. But to get into the Sharshari business was not as simple as

\footnotetext{
7 Alisebih is Djibouti's town where many Ethiopian traders are going there to buy tradable commodities.

8 According to my informants Dire Dawa was used to be the major market places of imported commodities where different commodities coming in from Djibouti were stationed and redistributed to different towns as far as Western Harerghe and central Ethiopia.
} 
you could imagine it. You need to know some Sharshari traders who already has established herself as a sharshari.... it needs some money I haven't had at that time. So I was working hard until I get what the Sharshari business requires to have.

From the above speech of Zahra, we can understand that some former women traders who haven't Sharshari relatives or family were doing some other business until they accumulate the required social capital in terms of friendship ties or working partners.

There were also Sharshari who was born in Dire Dawa. According to my informants and observations, majority of Dire Dawa born Sharshari were used to live in a place around Hafatal Issa ${ }^{9}$. Hafatal Issa was therefore, a place (quarter) where majority of Issa people who claim themselves as the founder of the city were used to live. According to my informant Abdulahi who is a CEO of the old railway company, most men settlers of Hafatal Issa were working within the railway company. Here, women were encouraged to go through and involve in trans-local trading business since their relative, neighbor or member of their family is working within the railway company.

Similar to the Sharshari trans-local traders of Dire Dawa, Malian women traders were also encouraged to join cross bordering trade through the railway because their husbands are working within the railway company [6]. Here Lambert has acknowledged the role of family backgrounds on encouraging women to join to trans-local trading business in between Mali and Senegal.

Generally, most of the Sharshari were from the city of Dire Dawa small towns where a railway station is available. According to my informants, ethnically Issa Somali women were claimed to be the majority since they were living in and around the areas where railway stations are available and their families were working within the railway company ${ }^{10}$.

\subsubsection{Economic Background}

Economic capital is the other form of capital in which a given traders needs to have in order to get in to the translocal trading field. My impression after visiting the border town and market of Dewelle is that Trans-local traders needs some more money since they are purchasing commodities as many as they afford to pay for it. Here, the more they bought commodities the more the get themselves into the market. However, when we see the economic background Sharshari traders, most of them were starting the business with very small amount of economic capital. According to my

9 According to elders of the city, Hafatal Issa is a geminated Somali language which means home of the Issa Somali clan. Therefore, majority of the residents of Hafatal Issa are ethnically Issa Somali whose economic activities were revolving around the railway company and its surrounding environs (Bourdieu (1987) call it social space)

10 Many Issa Somali are living in areas where railway line and railway stations are available. For instance, towns like Shinile, Adigala, Bigder, Dewelle and other small towns are dwelled by Issa Somali whose residents were working within the railway company as they were attracting many women traders from their ethnic groups. The domination of ethnically Issa workers in the railway corporation has is on historical background (see the background of this study). informants, this is because majority of traders rely on social networks and ethnic clinch in order to get into the Sharshari trans-local trading business.

As far as my informal conversation with Sharshari traders is concerned, majority of Sharshari traders had no job before their involvement in trading activity through the railways. The involvement of women in domestic activities and household productions have stated as the grand reasons why women failed to involve in income generating activities before their involvement to trans-local trading business. Especially those women who were living with their families were doing nothing than participating in household activities like preparing foods.

In order to join trans-local trading business, women who haven't the financial strength to commence trading business were either loan money from their relatives or ask their parents to help them get some money. One of my informants in this regard has told me that she had to steal her family's money to start the business.

Some women become Sharshari traders by inheriting the business from their families. My informant called Rawda, whose mother was Sharshari has said she started the business by using all the economic capital and financial support of her mother who was established and prominent Sharshari trader in Dire Dawa. Rawda added:

I used to distribute what my mother was bringing from Djibouti's market. I had the chance to see how profitable and rich my mother was. Hence, I was admiring the business that my mother was doing as it finally becomes my interest to join the business and become a Shershari. When i started the business, my mother gave me the money and inherited me her business networks she had built for decades.

According to Rawda therefore, the social and economic capitals she was inherited from her mother were helped her to get into the business. Other informants whose voices are not incorporated here are also stressed the importance of family background for women to break into the trans-local business across the railway towns of the eastern corridor of Ethiopia.

Generally as a form of capital which is used to get into trans-local trading activities, the above mentioned backgrounds had pivotal purposes in the process of helping individual women to break through the field of Sharshari business. Especially family background and connectivity to the dominant Issa Somali ethnic cliché were as important as it help individuals to get into and enjoy the business in a short period.

Trans-local trading activities of the Sharshari women was embedded with the art of self-entrepreneurship which is the act of organizing, creating and managing business ventures and assumes the risk for it. For instance, their action of smuggling commodities needs some sort of risk taking as the commodities might fall under the customary officers' hand. Moreover, market fluctuations both in terms of price and demand of commodities were common in trans-local business activities. However, Sharshari traders are capable of analyzing, understanding and predicting market behaviors which is decent characteristics of self-entrepreneurship. This 
art of being entrepreneur was therefore coming from nowhere but from early socialization of pupils, interaction, symbol and socio economic values in which Sharshari traders have grown up with.

Bourdieu's description of habitus should be traced here. According to Bourdieu's concept of habitus, individuals' routine activities within their environment and socialization during childhood stage has a great effect for the cognition, skill and behavior of individuals [7]. Here, Sharshari women of Dire Dawa were constructing their habitus (thoughts, tests, beliefs, interests and understandings) from their families during their childhood stages and inherit their families' business as they finally become sharshari trader by themselves.

\subsection{The Rationale Behind Women's Involvement in Trans-Local Business}

Beside of cultivating and yielding, many agrarian women across Africa prefer to sell their agricultural products by themselves [8]. Here they carry their agricultural products they have produced in agricultural fields and sell it in different market places. Thus, small scale women agriculturalists are not only producing seeds and fruits but they are also traders who sell their agricultural product to different markets sometimes by traveling beyond their localities. These two-folded activities of women are vital for their household economy since it enable them to generate income and satisfy food related demands of their family. Hence, many women across Africa are involved in trading activities despite some more burdens awaiting them at their households. Women are engaged in trading activities because trading activity earns them some amount of money they badly need to spend for some important goods that their family needs to purchase [9].

Coming to the Sharshari traders of Dire Dawa, there are a lot of factors why those women were involving to a business which need to travel a long way and cross international border. Here, those factors are organized under two major themes; push and pull factors.

\subsubsection{Push Factors}

Informants have stated two factors as a push factor that forced them to involve into trading activities through the railway. Here, the socio-economic impediments existed in women's household and the exposure of inheriting the business from parents are stated as the major push factors which were leading many women to the Sharshari trans-local business.

According to my informants, some women are involved in Sharshari business to generate income and ease their economic problems within the household. Here, women who are living around the railway stations were considering trading through the railway as a source of income which helps them to overcome economic problems of their respective families. Moreover, some other Women who came from distant areas were joining trading through the railway as it helps them to make money and send it for their families living in other areas.

Family background was the other push factor which triggered women to become Sharshari traders. Here, women whose family member was Sharshari traders have the opportunity to inherit business activities of their family members. Rawda Adam, whose parents were Sharshari traders, told me that she was highly influenced by the business that her family was engaged on.

Both my father and mother were Sharshari traders. They were respected persons within the community they live. They were profitable and rich Sharshari too. During my child age, I had the chance to see all those economic profits in which my parents were getting from this business activity; moreover, I was helping them by distributing the things they bring to Dire Dawa and $i$ was also collecting money from the shopkeepers who received commodities from my parents.

Here, women whose families used to be Sharshari traders get some sort of helps and encouragements from their families. The help of their family might include, introducing them with fellow Sharshari who can help them throughout their business activity, give them some money to start the business and inherit their customers. Therefore, some women were started trading business because their families who were already engaged in a Sharshari business encouraged them to trade commodities through the railway transportation.

Elsewhere in Africa, economic backgrounds of Families are the reason Nigerian women traders are widely involving in petty trading activities along big streets of the country. Women who come from groups with a strong tradition of trading tends to be the most active and those with traditional aversion to trade have a very little involvement in trading business. Similarly, women who come from a Sharshari trader's family and traditions have a great chance of following the footsteps of their relative [10].

VerEecke has further elaborated the concept of trade culture and ethics of women in the rural part of Nigeria. Inspired from VerEecke's conceptualization of trade culture and ethics, I am fully convinced that the Sharshari trans-local traders had also their own trade culture which is inherited, mutable and dynamic. As we can see the response of informant Rawda, trans-local trade was inherited business among the former Sharshari community. Moreover, its feature was also changing with the socio-economic scenarios along border areas and market settings [10].

\subsubsection{Pull Factors}

The amount of profits generated from the business, the existence of wider markets for imported goods and availability of cheap transportation service which transport both the traders and their commodities were some of the pull factors which were attracting women to engage into trading activity through the railways.

According to my informants, women traders were not only gaining income in the forms of money. Besides to that, the Sharshari and their families were benefited from the business in such a way that they satisfy materials demands of their family by bringing what they want from the Djibouti's 
markets. Here, those women always brings things like clothes (including jerseys for their son), electronics, rice, milk powders and edible oils for their household consumption. Hence, two-sided benefits of being a Sharshari trader were a pull factor for the involvement of many women in trans-local trading activities.

The availability of wider markets which awaits commodities coming in from border towns and markets of Ethiopia and Djibouti were the other catalyst which had been leading women to involve in trans-local trade. As a result of the wider demands for the commodities coming in from Djibouti, the Sharshari were not wondering for customers and fear to fail in business. The available cheap railway transportation which carries bunch of commodities of the Sharshari was the other attraction pulling women to the business. Railway in this regard was used both as a means of transportation of commodities and the place where many traders and residents living along the railway stations are interacting. Despite the key role that the sector was offering for trans-local traders, service charge was cheap. Here, according to informant Abdul-Aziz, a transportation cost paid for a given travel from Dire Dawa to Djibouti was only 100 birr including bunches luggage of traders.

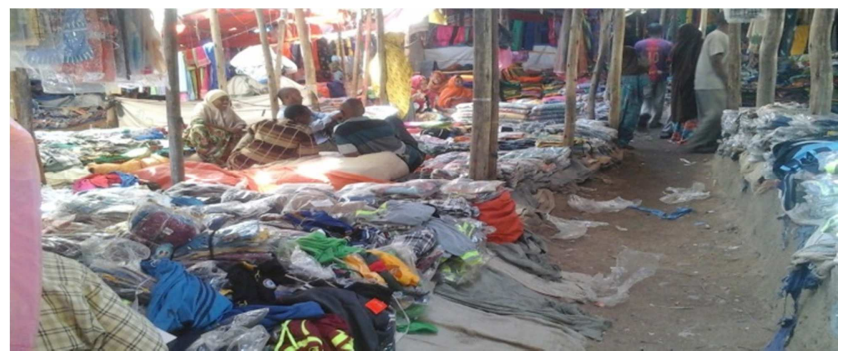

(Photo author: Tensay, Place: Ashowa/Dire Dawa, Date: April 23).

Figure 1. This is Ashowa market where Sharshari traders were exchanging their imported goods from Djibouti. The availability of wider markets like this one $i$ s believed to be the main reason why women are engaging in trans-local trading activities.

Generally, women merchants were involving to trans-local trading business due to two factors. These are the push and pull factors. Elsewhere in Africa, the economic crisis and market inflations of most of African countries are considered as the reason why trans-local women traders were mushroomed and many women were involved in such business [3]. In Asia, the Thai-Lao cross border women traders are emerged immediately after the decline of Soviet Union and the market disruptions after the decline of socialist states. Hence, when markets of a given country get disrupted, informal businesses including the trans-local and trans-border trade would the likely to be mushroomed [11].

\subsection{The Central Position of the Sharshari at the Level of Domestic Economy}

The dichotomy of public and domestic sphere has been the focus of social science in general and social anthropology in particular. For many social anthropologists therefore, active involvement of women in public sphere is highly determined by the burden of domestic activities in which many women have at their respective home [12]. Recently however, women are participating at least in different informal economic activities most importantly in the areas of trading along big streets of big cities. These traders are now started to speak about their life, they began to criticize political parties and they are critical of policies and strategies which are set to be implemented in their respective countries [13]. This really shows that how the coming out of women into the public spheres ${ }^{11}$ and income generating activities has changed the Longley lived saying of women to the domestic sphere and men to the public sphere dichotomy [14].

\subsection{Dual Responsibilities of Sharshari Traders}

Agent's Role is a proper sphere, a character or extent of activities in which an agent is expected to do. Within a given household therefore, parents have their own role to play [15]. The role in which a given agent assumes could be different in terms of the individual's or agent's willingness to hold it as well. Women Sharshari traders in this regard had dual roles within their household. These are the role of managing household activities and generating income for the overall expenditures made under the household's roof. Hence the central position and responsibilities of those women were claimed to be dual just to refer women's two different roles at their respective households.

\subsubsection{Managing Household Activities}

Perhaps the most important role that Sharshari traders have as a mother is being a provider-of a good home, managing proper nutrition and physical and emotional support for the member of the household. It may seems like never ending chore, but most women take motherhood like second nature the minute they are declared Hoyyo (respectful word used to call a mother). According to my key informants, even though the Sharshari mostly stay overnights out of their home, they always try to manage their households as well.

According to my informant Halima, who was working as a cooker within the Sharshari's home, women were managing their respective household. According to Halima, many Sharshari traders she know were providing what is needed within the home and order cockers what have to be done and what not within the house. Informant Halima added that:

Their husband has no power ${ }^{12}$ of ordering us what should we do and what not. It is the women who run every activity undertaken within the household. They control each and every steps of our activity. Even when they are heading to work, they order us everything we should do for their children and even for ourselves.

According to the above informant, some Sharshari traders were directly involved in to some activities of the household.

\footnotetext{
11 See footnote 1.

12 Power in this case is used to show the ability and decision making jurisdictions of women at domestic activities. According to my informant Halima, this power is not given to husbands or men because in Somali culture, men are not expected to involve in routine domestic activities. Even if they do, they will be criticized by the community and friends for that.
} 
My informant and former Sharshari whose name is Amina has told me that she was not happy and not satisfied with what the labor workers were doing within their home. Hence Amina preferred to cook meals when she was at home. Likewise, she was involving in washing clothes of the family. Informant Misky, has also reaffirmed that women control their household activities since their husbands role within the household was so much limited. Moreover, household productions like fun and pleasures making and holiday celebrations were mainly headed by those women traders.

\subsubsection{Women as Breadwinner of the Household}

In addition to managing household activities, Shershari traders were also bread winners of their respective households. Even though some of the Sharshari's husband had jobs, their income was not as sufficient as it cover all expenditures of the family. Hence, in most cases women merchants remain the sole source of income for their respective households. These women were responsible for covering the school fee of their children, payment for labors workers within the house, expenditures made for preparing food even though much of food stuffs were coming from Djibouti and some other important expenditure paid for amenities related issues.

Clearly, trading activities undertaken through the railway was the major source of income for those women. Here, those women were expected to travel such a long journey in between Dire Dawa and Djibouti, sat at different markets in and around the railway stations and undertake exchange activities with different consumers located in different small towns. It is after all these processes that those women were making money and spending for different expenditures made within their homes.

\subsection{The Issue of Gender and the Sharshari Women at Their Working Places}

Gender based discrimination exists in any country with some peculiar attribute [16]. There are two extremes of societies' perception on the role and gender issues. In some areas women are granted the lower status as they are only remained at home while some other societies like the Iroquois are giving the highest social status for women. Why is the status given for women across different societies are different? Such question is answered by the empirical evidences grasped from the societies it selves. Here, the social position and roles given for women within societies are presented as a determinant factor for the discrimination and gender based violence in which many women across the world are facing [12].

Social position of the Sharshari traders in this regard was believed to be positive as they remain leading figure of the power relation between and among different agents within their social space (railway stations). Moreover, because the Sharshari are situated in the top hierarchy of the power relation between agents within their social space, they actually face no or limited gender based attacks at their working place. According to my key informants, the
Sharshari traders were the one who were respected, feared and considered as powerful women. Presumably, the wider social and economic networks and their financial strength were believed to be the source of their peculiar social position and absence of gender based attacks to them.

Being member of the Issa Somali clan would also help to refrain from such attacks. Let alone to be discriminated and harassed, women of the Issa Somali clan were not dared to be confiscated by customary officers around different railway stations. Moreover, as far as my observation is concerned, gender based violence and discrimination is not huge concern as it is in other places.

Even though majority of informants have told me that there were no gender based violence at their working places, some few informants have admitted that they were facing the problem while trading through the railway. Here, after a deep investigation of informants, I am convinced that those who claimed the existence of gender based violence at their working places have relatively low social position and were out of the social and economic network platforms along their social space.

\section{Conclusion}

Cross border trading activities between Ethiopia and Djibouti was the main source of income for border towns like Dire Dawa from Ethiopia and Gunille from Djibouti side. The eastern corridor was therefore the economic hub for the two eastern African countries as well. This business on the other hand was carried out by women merchants who are locally called as Sharshari trader.

Despite some ambivalent conceptions of the society on the Sharshari traders' business, women Sharshari traders had positive social status within the society they used to live. The positive social status of the Sharshari traders is believed to be emanated from trader's participation in different social affairs of the community, success in their business, and economic strength that came from comparatively better income. In some cases moreover, ascribed social status had been granted to a person whose parents or relatives are Sharshari traders and basically from dominant Issa clanship. Here, such status has been granted even before the person's achievements and efforts.

Generally, deduced from empirical evidences and data gathered from the field, it is valid to claim and conclude that the Sharshari traders as an agent and Sharshari business as a field was a respected, valued, beneficial and widely practiced mode of subsistence for traders and stimulant of markets for residents of small towns along the railway lines of the eastern corridor.

\section{References}

[1] Shiferaw Bekele. 1987 Aspect of the History of Dire Dawa, 1902-1936. A Paper Presented at 4th Annual Seminar of the Department of History in Hawasa, July 8-12, 1978. 
[2] Baldet, Henry. 1972 Urban Study of Dire Dawa. Unpublished MA Thesis, Addis Ababa University.

[3] Muzvidziwa, V. 2005 Women without Borders: Informal Cross Border Trade among Women in South African Development CommunityRegion. Addis Ababa: OSSREA.

[4] Toksanbaeva, M. 2001 The Social Vulnerability of Women. Problems of Economic Transitions, Vol. 43: Issue 9, pp 72-83.

[5] Boserup, E. 1970 Women's Role in Economic Development. London: Earthscan Publisher.

[6] Lambert, Agnes. 1987 Une Alliance Tumultueuse: Les CommercantsMaliennes du Dakar- Niger et Les Agents del L'Etat Cahiers Des Science Humaines, Vol. 23: No. 1, pp 89103.

[7] Bourdieu, P. 1985 The Social Space and the Genesis of Groups. Theory and Society, Vol. 14: No 6, pp 723-744.

[8] Mutopo, P. 2010 Women Trading in Food across the Zimbabwe - South Africa Border: Experience and Strategies. Gender and Development, Vol. 18: No. 3, pp 465-477. Retrieved from, http://www.tandfonline.com/loi/cgde20.

[9] Muzvidziwa, V. 2001 Zimbabwe's Cross Border Women Traders: Multiple Identities and Response to New Challenges. Journal of Contemporary Studies, Vol. 19: No1, pp 67-80.
[10] VerEecke, C. 1993 Muslim Women Traders of Northern Nigeria: Perspective from the City of Yola, Ethnology, 217236.

[11] Phadungkiati, L. \& Connell, J. 2014 Social Networks as Livelihood Strategies for Small Scale Trades on the Thai-Lao Border. Australian Geographer, Vol. 45: No 3, pp375-391. Retrieved from http://www.tandfonline.com/loi/cage20.

[12] Lewellen, T. C. 2003 Gender and Power in Political Anthropology: An Introduction (3rded.). Praeger: Westport and London.

[13] Grey-Johnson, C. 1992 The African Informal Sector at the Cross Roads: Emerging policy Options. African Development, Vol. 18, No 1. Pp 65-91.

[14] Rosaldo, Michellez. 1974 Women Culture and Society: A Theoretical Overview. In Michellez Z. Rosaldo and Louis Lamphere (eds.). Women, Culture and Society. Stanford: Stanford University press.

[15] Bourdieu, P. 1989 Social Space and Symbolic Power. Sociological Theory, Vol. 17: No. 1, pp 14-25.

[16] Gaidzanwa, R. B. 1998 Cross Border Trade in Southern Africa: a Gendered Perspective. Harare: Sapes Book. 